\title{
Relações entre filões de fluorita, rochas da Bacia do Paraná e lineamentos de direção NW-SE no Sudeste Catarinense: implicações para a prospecção
}

\author{
Mateus Marcili dos Santos Silva ${ }^{1}$, Artur Cezar Bastos Neto ${ }^{1}$ \& Michael Holz ${ }^{1}$
}

\begin{abstract}
Resumo Os filões de fluorita mesozóico-terciários do distrito de Santa Catarina são associados a lineamentos NNE-SSW. Nestes, a localização preferencial dos filões se situa nas intersecções com lineamentos NW-SE e nas proximidades de relictos de rochas paleozóicas da Bacia do Paraná. O trabalho visou ao entendimento destas relações através do estudo detalhado das rochas sedimentares em uma área onde ocorrem filões de fluorita na intersecção de dois lineamentos com estas direções. No lineamento NW-SE ocorre uma seqüencia sedimentar onde foram identificadas 7 associações faciológicas e 3 superfícies cronoestratigráficas. A evolução tectono-sedimentar encontrada indica que a sedimentação da bacia na área do distrito foi essencialmente controlada por estas estruturas NW-SE que criaram zonas com cobertura sedimentar mais espessa, uma condição necessária para a formação dos filões de fluorita e um dos fatores controladores da distribuição dos filões em escala regional. A migração dos fluidos mineralizantes em profundidades maiores foi fortemente controlada pelas estruturas do NW-SE. Após a ascensão até o nível da base da cobertura sedimentar, eles migraram longitudinalmente pelas estruturas NNE-SSW, depositando fluorita e estabelecendo gradientes geoquímicos em escala local. Os filões mais próximos da interseç̧ão são os que possuem minério com maior teor de fluorita.
\end{abstract}

Palavras-chave: estratigrafia de seqüências, lineamento de Urussanga, filão, fluorita, Santa Catarina, Bacia do Paraná.

\begin{abstract}
Relationship between fluorite veins, Paraná Basin rocks and NW-SE lineaments in the southeastern Santa Catarina: implications for fluorite prospecting. The tertiary-mesozoic fluorite veins in the Santa Catarina fluorine mining district are associated to NNE-SSW lineaments. Along these lineaments, the fluorite ore veins are mainly located at the intersections with NW-SE lineaments and near to Paleozoic relicts rock of the Paraná Basin, even in uplifted areas further east. The aim of this study is to understand the relationships among these lineaments and associated sediments and fluorite veins. The use of sequence stratigraphy in sediments associated to the Urussanga lineament (NW-SE) allowed the identification of three cronostratigraphycs surfaces and seven facies associations. The tectono-sedimentary evolution observed indicates that the sedimentation basin in the district area was essentially controlled by the NW-SE structures which generated areas with thicker sedimentary cover, a necessary condition for the formation of fluorite deposits. The hydrothermal fluids migration in greater deep was mainly controlled by the NW-SE structures. After rising up to the basal level of the sedimentary cover, the fluids migrated longitudinally along the NNE-SSW structures, depositing fluorite and establishing geochemical gradients that controlled the formation of deposits at a local scale.
\end{abstract}

Keywords: sequence stratigraphy, Urussanga lineaments, fluorite deposits, Paraná Basin, Santa Catarina.

INTRODUÇÃO A primeira referência à existência de mineralização filoneana de fluorita no Sudeste Catarinense (Fig. 1) deve-se a Putzer (1953). Ainda nos anos 50, a fluorita foi explorada artesanalmente. Nos anos 70, o distrito fluorítico de Santa Catarina (DFSC, Fig. 2) já era o maior produtor de fluorita da América do Sul, posição que ainda ocupa. O auge da produção ocorreu nos anos 80 (em torno de 300.000 t/ano de minério com teor médio de $35 \%$ de $\mathrm{CaF}_{2}$ ). As reservas descobertas totalizam cerca de $6,5 \mathrm{Mt}$ de minério in situ, das quais restam apenas cerca de $1 \mathrm{Mt}$ a serem lavradas, implicando novos investimentos em pesquisa mineral e apoio a estudos que permitam o aperfeiçoamento dos critérios prospectivos.
O estudo pioneiro de Angeiras \& Teixeira (1965) relacionou a mineralização ao magmatismo granítico. Pouco depois, Teixeira (1969) verificou que os filões de fluorita também cortam as rochas da Bacia do Paraná. Assim, os modelos genéticos subsequentes propuseram idades menores e, de diferentes formas, ligaram o controle da mineralização à reativação de estruturas do embasamento pela tectônica da margem continental. Horbach \& Marimon (1980) associaram as mineralizações ao magmatismo alcalino de Lages (65Ma, Scheibe 1986). Morgental (1984) associou ao magmatismo alcalino de Anitápolis (129Ma, Amaral 1967). Savi (1980) e Savi \& Dardenne (1980) consideraram que os filões foram formados pelo flúor lixiviado 


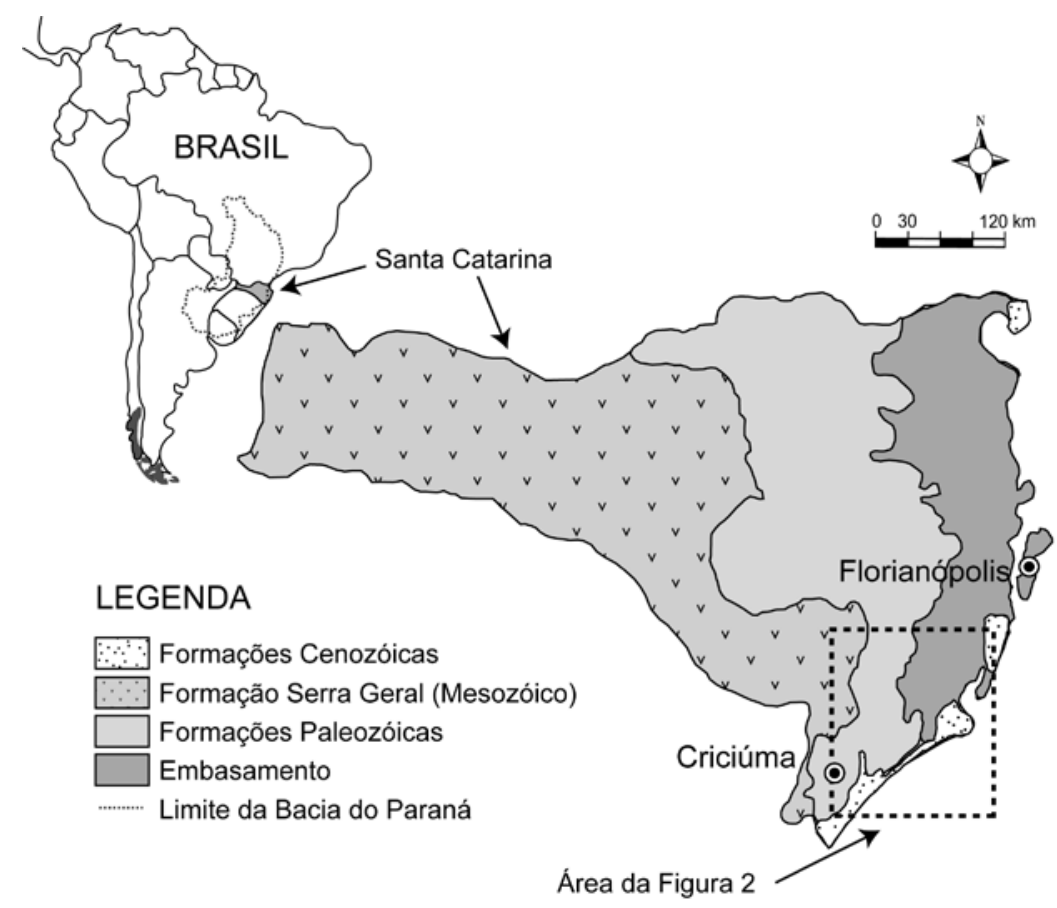

Figura 1 - Mapa de localização do distrito fluorítico de Santa Catarina.

de granitos por soluções hidrotermais envolvidas em circuitos convectivos causados por anomalia térmica relacionada ao rifteamento do Atlântico Sul. Independentemente dos modelos adotados, estes autores apontaram dois critérios prospectivos até hoje considerados os mais importantes pelos geólogos do distrito: (a) a associação da mineralização a lineamentos N-S a NNE-SSW, com localização preferencial dos filões nas proximidades de intersecções com lineamentos de direção NW-SE e (b) a localização dos filões abaixo ou nas imediações de relictos da cobertura sedimentar que os protegeram da erosão.

A partir dos anos 80, estudos detalhados enfocaram os mais diversos aspectos da geologia do distrito, como, por exemplo, a caracterização dos filões (Bastos Neto 1990, Rocha 1997, Martins et al. 2003) e sua datação (Tassinari \& Flores 1992, Jelinek 1997, 2002), a investigação das fontes do F (Sallet 1988, Sallet et al. 1996) e das soluções hidrotermais (Bastos Neto et al. 1996), a tectônica transcorrente dos lineamentos NNESSW (Hackspacher \& Flores 1987, Ferreira \& Almeida 1989), a prospecção (Morgental 1985) e a identificação de novas estruturas (Hoff 2002, Hoff et al. 2002). Estes e outros trabalhos também contribuíram para prospecção, identificando e discutindo novos critérios, entretanto, não abordaram o papel exercido pelas estruturas NW$\mathrm{SE}$, nem investigaram que processos geológicos - síncronos ou posteriores à sedimentação - teriam permitido a preservação de parte da cobertura, mesmo em locais afetados por soerguimento e que, em alguns casos, distam mais de duas dezenas de $\mathrm{km}$ da atual borda da bacia.

$\mathrm{O}$ presente trabalho objetiva contribuir para $\mathrm{o}$ preenchimento das lacunas de conhecimentos acima re- feridas. Aárea de estudo foi a parte sul do DFSC (Fig. 3), onde o lineamento mineralizado Canela Grande, de direção NNE-SSW, intercepta o lineamento de Urussanga, de direção NW-SE. Neste local ocorre - em grande parte mascarado pela cobertura aluvionar, mas evidenciado por sondagens rotativas e geofísica executada pelos mineradores - um pacote de rochas sedimentares que, por sua espessura excepcional e por apresentar em sua parte exposta (NW) limites definidos por falhas, originou, entre os geólogos das mineradoras de fluorita, a denominação informal de graben de Urussanga. O emprego das técnicas modernas de estratigrafia de seqüências faz com que o trabalho represente também uma contribuição para a estratigrafia da Bacia do Paraná em Santa Catarina.

\section{CONTEXTO GEOLÓGICO}

Estratigrafia O DFSC (Fig. 2) ocupa uma faixa de cerca de $100 \mathrm{~km}$ por $30 \mathrm{~km}$, delimitada a oeste pela Bacia do Paraná e a leste pelo Atlântico Sul. O embasamento faz parte da porção NE do Batólito Pelotas, unidade geotectônica central do Cinturão Dom Feliciano (Fragoso César 1980). Para simplificação do mapa (Fig. 2), as rochas do embasamento não foram diferenciadas. Elas pertencem ao Complexo Granito-Gnáissico e às Suítes Intrusivas Pedras Grandes e Tabuleiro (Sallet 1988). São cortadas por diques de rochas subvulcânicas ácidas eocambrianas (Teixeira 1969).

A Bacia do Paraná é constituída por um conjunto de rochas sedimentares com idades entre o Neoordoviciano e o Neocretáceo que abrange uma área de aproximadamente $1.500 .000 \mathrm{~km}^{2}$. Possui um formato alongado na direção NNE-SSW com aproximadamente 


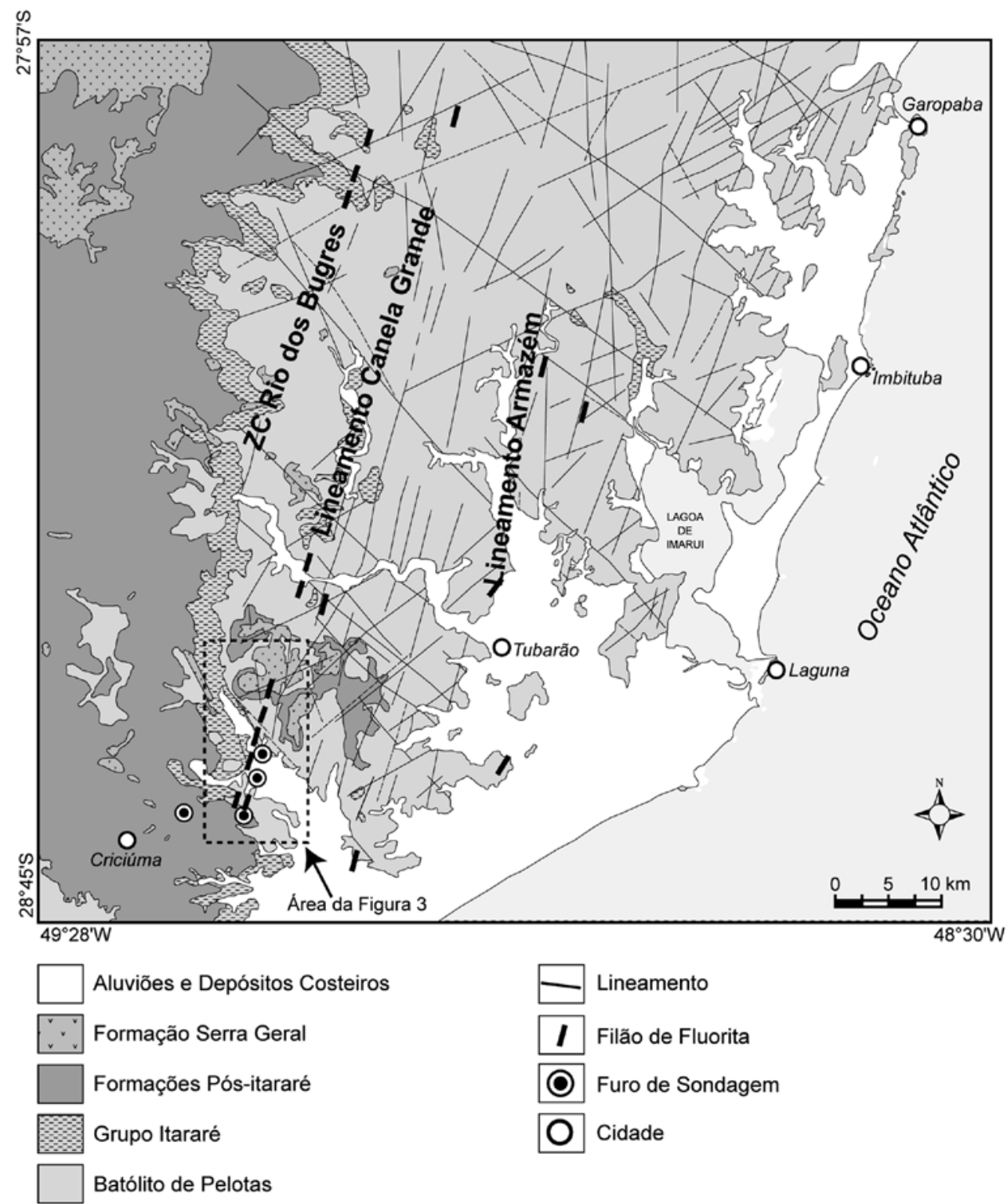

Figura 2 - Mapa geológico do distrito fluorítico de Santa Catarina (modificado de Morgental \& Kirchner 1983 e Jelinek 2002).

$1750 \mathrm{~km}$ de comprimento e com uma largura média de $900 \mathrm{~km}$, fazendo parte de territórios brasileiro, argentino, uruguaio e paraguaio. É uma bacia cratônica flexural, de evolução policíclica, cujo preenchimento iniciou no Ordoviciano, aparentemente sem um rifte precursor (Zalán et al. 1990). Seu preenchimento sedimentar compreende seis superseqüências deposicionais, que perfazem um total de aproximadamente 6000 metros de espessura (Milani 1997). As rochas da Bacia do Paraná do distrito pertencem às unidades litoestratigráficas Rio do Sul, Rio Bonito (Membros Triunfo e Paraguaçu) e Palermo, todas temporalmente situadas no Permiano Inferior. Estas são cortadas localmente por diques e soleiras de diabásio da Formação Serra Geral, do Juro-Cretáceo.

A Formação Rio do Sul é constituída basicamente por rochas glacio-marinhas assentadas sobre o embasamento cristalino. Sua porção basal (Krebs \&
Menezes Filho 1984) consiste de um espesso pacote de folhelho negro (folhelho Lontras) depositado em ambiente marinho profundo. Acima dos folhelhos há um pacote de turbiditos pelito-arenosos e de turbiditos areno-pelíticos representativos de leques submarinos, associados a diamictitos e arenitos fluidizados, que constituem a fácies de talude. Sobre estes depósitos ocorrem sedimentos de frente deltáica, indicando o início da progradação dos sedimentitos da Formação Rio Bonito. Esta é constituída basicamente por rochas de origem flúvio-deltáica e marinho rasa, com pacotes de até $150 \mathrm{~m}$ de espessura formados por arenitos de graulometria fina/grossa a conglomerática e por sedimentos pelíticos a argilosos. A formação Rio Bonito é portadora de camadas de carvão exploradas desde a década de quarenta. Em Santa Catarina, esta unidade foi dividida em três membros: Triunfo, Paraguaçu e Siderópolis 


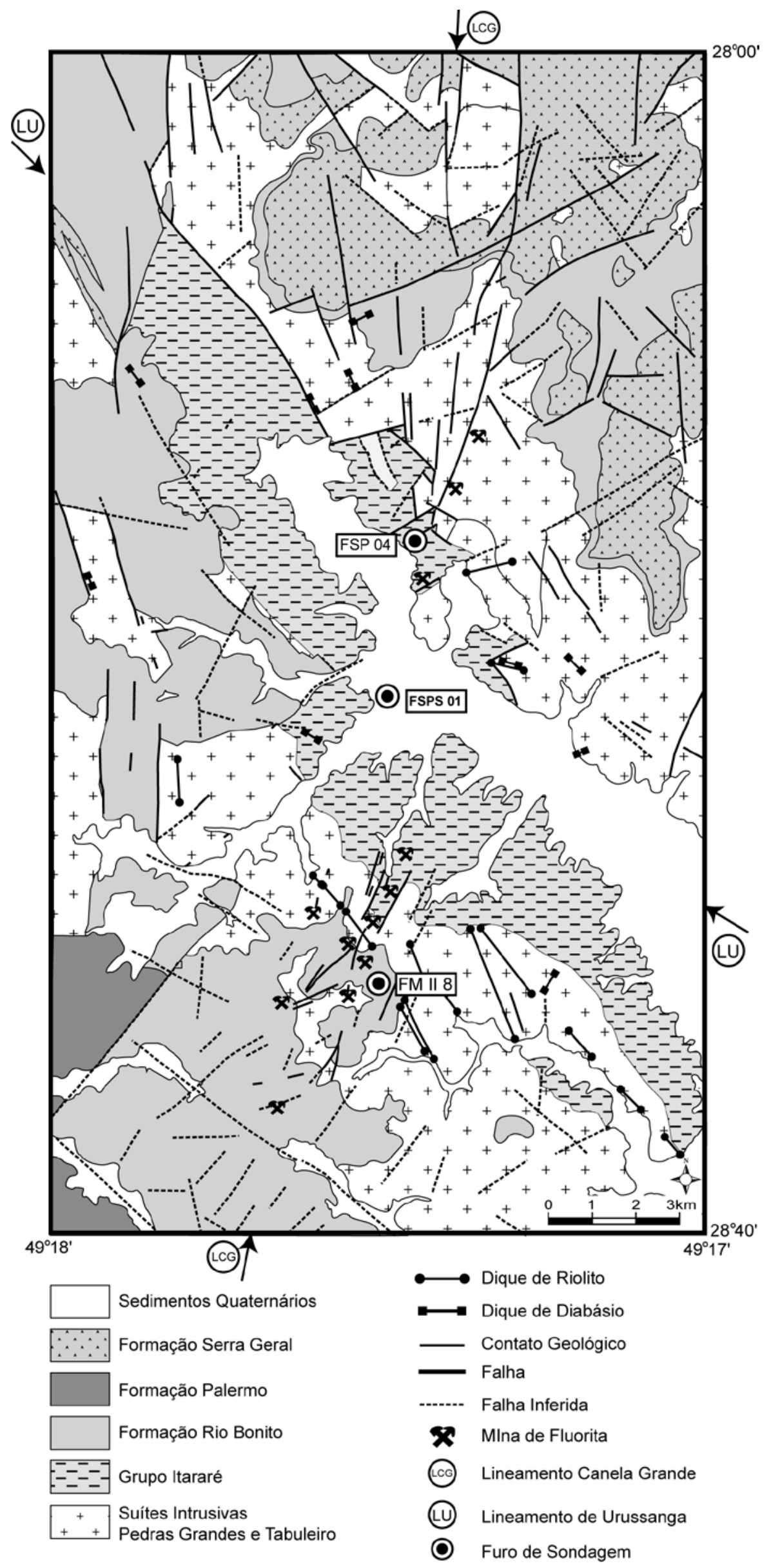

Figura 3 - Mapa geológico da área onde se intersectam lineamentos Canela Grande e Urussanga (localização na figura 2). 
(Schneider et al. 1974). O contato superior (litoestratigráfico) é concordante com a Formação Palermo que é eminentemente pelítica, constituída por siltitos cinza a amarelos, apresentando intensa bioturbação, e raras lentes de arenitos finos a conglomeráticos. Apresenta frequentemente estruturas do tipo hummocky cross stratification, flaser, wavy e linsen, indicando ambiente deposicional de shoreface e plataforma marinha (Walker 1992). A Formação Serra Geral no distrito é representada por diques e soleiras de diabásio. Na parte norte do distrito ocorre o maciço alcalino de Anitápolis (129 Ma, Amaral et al. 1967).

Arcabouço estrutural e mineralizações de fluorita As principais estruturas do DFSC (Fig. 2) enquadram-se em 3 grupos: NNE-SSW, NW-SE e ENEWSW. As duas primeiras direções correspondem a lineamentos que se estendem muito além dos limites do distrito (Fig. 4). Os lineamentos NW-SE da região foram identificados por Putzer (1953). Eles formam um conjunto de 6 lineamentos principais limitados ao norte pelo lineamento de Garopaba e, ao sul, pelo de Urussanga (Fig. 4), assim denominados por Horbach \& Marimon (1980) que os consideraram como estruturas do embasamento afetadas por sucessivas reativações. O lineamento Canela Grande é a principal estrutura do grupo NNE-SSW, tem pelo menos $150 \mathrm{~km}$ de comprimento, $2 \mathrm{~km}$ de largura e corresponde a uma zona de cisalhamento brasiliana (Hackspacher \& Flores 1987, Ferreira \& Almeida 1989).

A maior parte dos depósitos de fluorita explorados está associada ao lineamento Canela Grande (Fig. 2). A oeste deste, ocorre o subdistrito Grão Pará controlado pela zona de cisalhamento Rio dos Bugres (Ferreira \& Almeida 1989). A leste, o lineamento Armazém controla três depósitos e inúmeras ocorrências. São conhecidos, ainda, alguns filões não relacionados aos 3 lineamentos citados.

A mineralização é do tipo filoneana hidrotermal de baixa temperatura (temperatura de homogeneização das inclusões fluidas na fluorita entre $100^{\circ} \mathrm{C}$ e $180^{\circ} \mathrm{C}$ ), depositada por fluidos de salinidade $<2 \%$ eq. $\mathrm{NaCl}$ (Bastos Neto 1990). Os filões são encaixados preferencialmente nos granitos, estreitando-se dentro das rochas da Bacia do Paraná. Associam-se a falhas e fraturas de direção N-S a ENE-WSW com mergulho em geral subvertical. Têm comprimento de até $1 \mathrm{~km}$, espessura de até $15 \mathrm{~m}$ e extensão vertical de até $300 \mathrm{~m}$. São essencialmente constituídos por fluorita e quartzo. A abertura/preenchimento das estruturas filoneanas ocorreu ao longo de 4 fases tectônicas. Os minérios das quatro fases distinguem-se por suas texturas, suas cores, seus conteúdos de elementos traço na fluorita e pelos minerais acessórios (Dardenne et al. 1997, Bastos Neto et al. 1992). A datação do hidrotermalismo que afetou as encaixantes por traços de fissão em apatita indica dois episódios de formação para os filões do lineamento Canela Grande ( $120 \mathrm{Ma}$ e $\sim 70 \mathrm{Ma})$ e idades entre de 70Ma a 40Ma para os filões da parte oeste do DFSC (Jelinek 1997 e 2002).
GEOLOGIA DA ÁREA DE ESTUDO A área de estudo (Fig. 3) foi mapeada na escala 1:25.000. O embasamento é constituído pelos granitos Pedras Grandes e Tabuleiro, cujas delimitações no mapa foram eliminadas para facilitar a visualização de outras feições mais importantes. As rochas sedimentares pertencem ao Grupo Itararé, Formação Rio Bonito e Formação Palermo. Os lineamentos Canela Grande (NNE-SSW) e Urussanga (NW-SE) se cruzam na parte central da área mapeada.

A Formação Rio do Sul ocorre essencialmente associada ao lineamento de Urussanga, existindo também algumas ocorrências não cartografáveis ao sul do mesmo. As Formações Rio Bonito e Palermo ocorrem especialmente na parte sudoeste da área, onde a primeira tem espessura muito uniforme, da ordem de $30 \mathrm{~m}$, forma um platô que recobre os filões de fluorita e é cortada pelas falhas que controlam a mineralização, com rejeitos verticais de no máximo $15 \mathrm{~m}$. Na parte nordeste da área, os afloramentos de rochas sedimentares são parcialmente cobertos pelos colúvios das soleiras de diabásio. Mesmo assim, a zona de afloramento é bem delimitada no campo, mostrando-se bastante contínua, apenas localmente afetada por deslocamentos verticais de até $20 \mathrm{~m}$ que podem ser tectônicos e/ou ligados à intrusão. Essas rochas foram tentativamente correlacionadas à Formação Rio Bonito, em uma interpretação que corrobora Morgental (1984), mas que difere do mapa regional (Silva 2000) onde foram correlacionadas à Formação Rio do Sul. Na área estudada há bons afloramentos apenas na sua metade noroeste.

O lineamento de Urussanga é marcado no campo por faixas de rochas cataclásticas, por veios de quartzo, e por diques de rochas subvulcânicas ácidas eopaleozóicas e de diabásio da Formação Serra Geral. Os diversos diques e as rochas cataclásticas se dispõem paralelamente à direção NW-SE, numa faixa com largura em torno de $4 \mathrm{~km}$. Este lineamento desloca sinistralmente o lineamento Canela Grande, impondo um rejeito da ordem de $2 \mathrm{~km}$. No lineamento de Urussanga, ocorre o graben homônimo. A borda do graben, com direção geral NW-SE, é claramente afetada pela intersecção com o lineamento Canela Grande, sofrendo modificações de direção ao seguir localmente as estruturas do último, mais especialmente na parte norte (Fig. 3). Assim como em outras partes do DFSC, as estruturas NW-SE são as principais controladoras do hidrotermalismo ativo no distrito, manifesto em inúmeras fontes termais situadas na borda do graben.

O lineamento Canela Grande é constituído por um sistema de falhas de direção N-S e NNE-SSW a NE-SW. Em afloramentos na parte norte da área, ocorrem estrias indicativas de movimentação sinistral das falhas N-S, interpretada como a fase de movimentação mais antiga. As reativações na época da formação dos filões de fluorita foram identificadas por Bastos Neto (1990) nas minas de fluorita. Inicialmente, as estruturas movimentaram-se destralmente (fase de mineralização 1), afetando diques de diabásio NW-SE, sendo um deles datado $(\mathrm{Rb} / \mathrm{Sr})$ em 131Ma (Teixeira 1969). Subsequentemente, foram reativadas como falhas normais em resposta a uma extensão NW-SE (fase de mineralização 


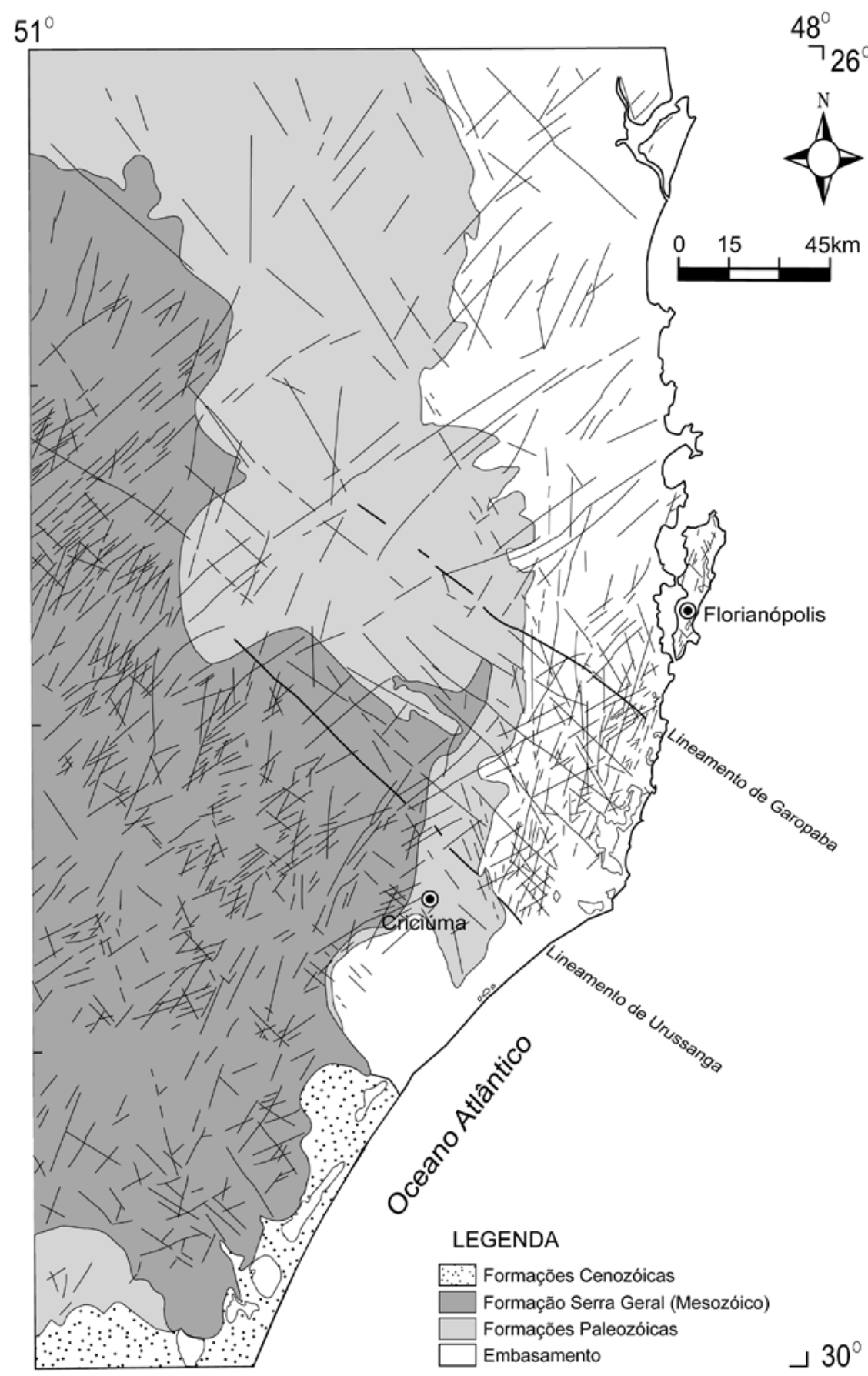

Figura 4 - Principais lineamentos da parte leste de Santa Catarina (modificado de Bastos Neto 1990).

2) observada em todo o distrito e correlacionada com o estágio rifte de abertura do Atlântico, no sentido de Asmus (1984). Duas outras reativações do lineamento Canela Grande, correspondentes às fases de mineralização 3 e 4, foram identificadas apenas nas minas de fluorita, sendo a última datada em 70Ma (Jelinek 1997).

Dentre todos os depósitos de fluorita da área, os maiores são os filões São Pedro e Segunda Linha Torrens Principal, os únicos situados no domínio do graben, respectivamente nas bordas norte e sul. No primeiro, observa-se, no subsolo, na parte sul da mina, o filão de fluorita na estrutura $\mathrm{N} 20^{\circ} \mathrm{E}-75 \mathrm{NW}$, tendo na capa as rochas do graben e na lapa o granito. Sobre o último filão, a espessura da cobertura sedimentar aumenta progressivamente na direção norte, atingindo $150 \mathrm{~m}$ na extremidade do depósito. Diante da possibilidade de que espessuras de cobertura ainda maiores ocorressem na direção norte, inviabilizando economicamente a exploração de depósitos porventura existentes, os mineradores contrataram a CPRM para efetuar sondagens geofísicas por eletro-resistividade. Os resultados (Bastos Neto 1986, 1990) revelaram um mosaico de blocos altos e baixos, podendo alcançar uma profundidade do embasamento de até $300 \mathrm{~m}$. 
ESTRATIGRAFIA DO GRABEN DE URUSSANGA E ADJACÊNCIAS Os processos sedimentares atuantes em cada ambiente deposicional foram identificados e interpretados procurando sempre a eles associar o controle estrutural. $\mathrm{O}$ estudo fundamentou-se no exame e descrição de testemunhos de sondagens e de afloramentos, objetivando o reconhecimento de fácies, associações de fácies, tratos de sistemas e seqüências deposicionais, analisados sob a óptica da estratigrafia de seqüências. Foram analisados os testemunhos de 3 sondagens efetuadas pela Companhia Nitro Química (Tab. 1): os furos FSPS 01 e FSP 04 efetuados no graben; o furo FM II8 que corta a cobertura sedimentar imediatamente ao sul do graben (Figs. 2 e 3). Para correlação com rochas da Bacia do Paraná mais distantes do graben, foi descrito o furo PB 05 (Fig. 2) do Projeto Barro Branco da CPRM, realizado durante a década de 80 .

Interpretação de fácies e associações de fácies As variedades faciológicas foram diagnosticadas conforme Walker (1992), que define fácies como "um corpo de rocha caracterizado por uma combinação particular de litologias, estruturas físicas e biológicas, que o diferencia dos corpos de rochas sobrepostos, sotopostos e lateralmente adjacentes". As descrições e nomenclatura das fácies reconhecidas constam na tabela 2 . As fácies foram agrupadas em 7 associações faciológicas (AF), a seguir abordadas do ponto de vista de processo e evolução paleoambiental. Correlações entre associações faciológicas e litoestratigrafia constam na figura 5 .

ASSOCIAÇÃO FACIOLÓGICA I É constituída por diamictitos, ritmitos e arenitos finos a grossos com laminação climbing ripples e plano-paralela associadas esporadicamente com grânulos e seixos. A espessura total atinge cerca de $60 \mathrm{~m}$. Os diamictitos foram interpretados como resultado de deslizamentos do material situado na borda do graben, onde, provavelmente, a topografia seria mais acentuada. $\mathrm{O}$ sedimento ali contido, após ter sido desestabilizado, foi transportado através de fluxo de massa (debris flows), no qual o material mais grosso, imaturo e mal selecionado tende a se depositar numa zona mais proximal. Já os sedimentos mais finos, que dão origem aos depósitos rítmicos, foram levados em direção ao depocentro da "bacia" através de correntes de turbidez gerando lâminas alternadas de silte e argila. Os seixos foram interpretados como clastos pingados liberados por ocasião do degelo de icebergs.

ASSOCIAÇÃO FACIOLÓGICA II Esta AF se destaca das demais pela espessura de cerca de $250 \mathrm{~m}$. É comum a ocorrência de laminação provocada por ação de ondas e correntes, característica de ambiente marinho raso. Os estratos com registro de bioturbação tornam-se mais freqüentes da base para o topo. Dias (1993), em estratos correlatos a esta AF no Rio Grande do Sul, indicou a ocorrência de bioturbações marinhas do tipo tasmanites e acritarca. Os pelitos e arenitos desta $\mathrm{AF}$ são interpretados como registro de inundação da bacia, recobrindo, portanto, durante a
Tabela 1 - Coordenadas e metragem dos furos de sondagem utilizados para correlação estratigráfica.

\begin{tabular}{c|c|c|c}
\hline $\begin{array}{c}\text { Furos de } \\
\text { sondagem }\end{array}$ & $\begin{array}{c}\text { Metragem } \\
\text { descrita }\end{array}$ & \multicolumn{2}{|c}{ Coordenadas UTM } \\
\hline FSPS-01 & $403 \mathrm{~m}$ & 6836771 & 670163 \\
FSP-04 & $143 \mathrm{~m}$ & 6838250 & 670950 \\
FM II-8 & $47 \mathrm{~m}$ & 6831313 & 669623 \\
PB-05 & $190 \mathrm{~m}$ & 6832015 & 661130 \\
\hline
\end{tabular}

fase transgressiva no fim do ciclo deposicional do Itararé, toda a associação de fácies I. Estas duas primeiras AF são correlacionadas à Formação Rio do Sul.

ASSOCIAÇÃO FACIOLÓGICA III É constituída rochas sedimentares com estratificação lenticular, laminação climbing ripple e laminação plano-paralela associada a decantação de sedimentos argilosos e matéria orgânica. Sua espessura atinge cerca de $40 \mathrm{~m}$. A AF é interpretada como gerada em ambiente de frente deltáica, marcando o início da progradação do sistema fluvio-deltáico que se instalou na região.

ASSOCIAÇÃO FACIOLÓGICA IV Esta AF é constituída por arenitos de textura fina a grossa/conglomerática com gradação normal e estratificação cruzada acanalada incipiente. Ocorrem intercalações de pacotes pelíticos carbonosos, lateral e verticalmente associados. Sua espessura atinge cerca de $70 \mathrm{~m}$. Esta AF foi considerada a continuação do processo de progradação da porção mais continental do sistema flúvio-deltáico

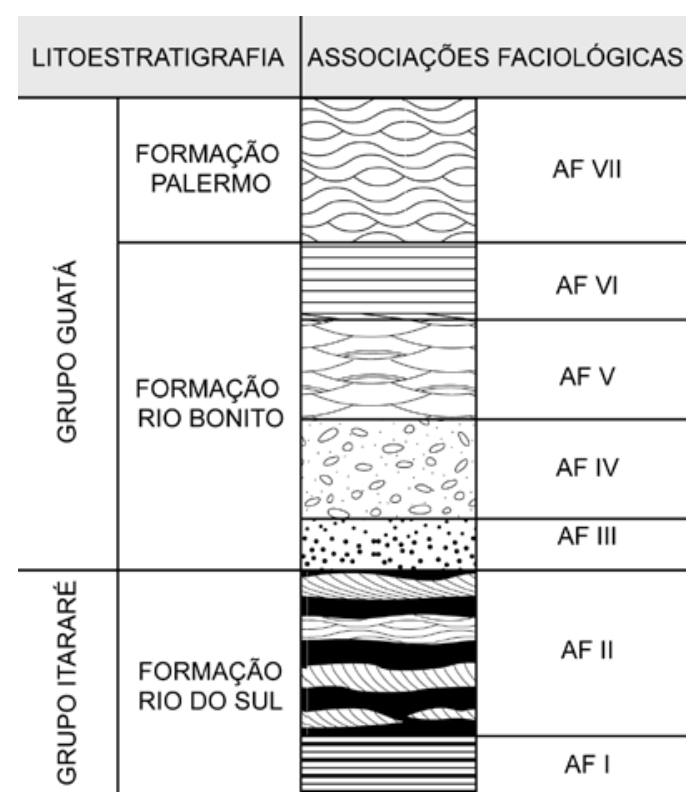

Figura 5 - Correlação entre litoestratigrafia e associações faciológicas da área de estudo (AF: associação faciológica). 
Tabela 2 - Descrição e interpretação das litofácies identificadas na área de estudo.

\begin{tabular}{|c|c|c|c|}
\hline FÁCIES & LITOLOGIA/TEXTURA & ESTRUTURA SEDIMENTAR & INTERPRETAÇÃO \\
\hline $\mathrm{Gm}$ & $\begin{array}{l}\text { Conglomerado matriz- } \\
\text { suportado }\end{array}$ & ausente & Fluxo de massa (debris-flow) \\
\hline $\mathrm{Gc}$ & $\begin{array}{l}\text { Conglomerado clasto- } \\
\text { suportado. }\end{array}$ & $\begin{array}{l}\text { Gradação normal, estratificação cruzada } \\
\text { acanalada }\end{array}$ & $\begin{array}{l}\text { Migração de dunas subaquosas por regime de } \\
\text { fluxo inferior de muito alta energia }\end{array}$ \\
\hline $\mathrm{Gi}$ & Conglomerado intraclástico & ausente & $\begin{array}{c}\text { Retrabalhamento e exposição dos sedimentos } \\
\text { e posterior litificação }\end{array}$ \\
\hline $\mathrm{Sb}$ & Arenito muito fino & $\begin{array}{c}\text { Bioturbação, } \\
\text { tasmanites e acritarca }\end{array}$ & $\begin{array}{l}\text { Migração de dunas e ripples subaquosas } \\
\text { por regime de fluxo inferior de baixa energia, } \\
\text { baixa taxa de sedimentação }\end{array}$ \\
\hline St & Arenito fino a grosso & Estratificação cruzada planar/acanalada & $\begin{array}{l}\text { Migração de dunas e ripples subaquosas por } \\
\text { regime de fluxo inferior de alta energia }\end{array}$ \\
\hline $\mathrm{Sf}$ & Arenitos finos a médios & Estratificação do tipo flaser e drapes & $\begin{array}{l}\text { Alternância entre migração de formas de leito } \\
\text { e decantação }\end{array}$ \\
\hline $\mathrm{Sw}$ & Arenitos finos a médios & $\begin{array}{c}\text { Combinação de laminação por onda } \\
\text { e corrente (incluindo hummocky } \\
\text { em pequena escala), e algumas } \\
\text { bioturbações }\end{array}$ & $\begin{array}{l}\text { Alternância de fluxos de baixa energia com } \\
\text { influência de ondas }\end{array}$ \\
\hline Ss & Arenitos finos a médios & Estratificação swash & $\begin{array}{l}\text { Deposição sob condições de alta energia } \\
\text { (regime de fluxo superior) }\end{array}$ \\
\hline Shes & Arenito fino & $\begin{array}{c}\text { Estratificação hummocky e swaley } \\
\text { cross bedding, em algumas vezes com } \\
\text { presença de siderita }\end{array}$ & $\begin{array}{l}\text { Depósitos de sedimento em suspensão sob } \\
\text { influência de ondas de alta energia (ondas de } \\
\text { tempestade }\end{array}$ \\
\hline $\mathrm{R}$ & Ritmitos (silte/argila) & $\begin{array}{l}\text { Estratificações milimétricas plano- } \\
\text { paralelas, por vezes irregulares, com } \\
\text { freqüentes escorregamentos }\end{array}$ & $\begin{array}{l}\text { Regime de fluxo inferior de baixa energia, } \\
\text { alternando-se com decantação de sedimentos } \\
\text { em suspensão }\end{array}$ \\
\hline MS & Argilito e arenito fina & $\begin{array}{l}\text { Estratificação lenticular, por vezes } \\
\text { associadas com laminação climbing } \\
\text { ripple, freqüentes escorregamentos }\end{array}$ & $\begin{array}{l}\text { Migração de ripple em condições de regime } \\
\text { de fluxo inferior combinado com decantação } \\
\text { de sedimentos em suspensão }\end{array}$ \\
\hline $\mathrm{Mb}$ & Argila e areia muito fina & $\begin{array}{l}\text { Bioturbação, por vezes com } \\
\text { estratificação lenticular }\end{array}$ & Decantação de sedimentos em suspensão \\
\hline MR & Argilito com marca de raiz & Brechas, birdseyes, por vezes flaser & $\begin{array}{l}\text { Decantação de sedimentos em suspensão } \\
\text { alternando com possível exposição subaérea }\end{array}$ \\
\hline$C C$ & Carvão e folhelho carbonoso & Marcas de raiz & $\begin{array}{l}\text { Acumulação agradacional de sedimentos } \\
\text { muito fino e de restos vegetais }\end{array}$ \\
\hline
\end{tabular}

sobre os arenitos finos da AF-III. Os arenitos corresponderiam à barra de migração (e.g., Miall 1992), e as porções mais grossas foram interpretadas como lobos de canais distributários (e.g., Bhattacharya \& Walker 1992). Os pacotes pelíticos carbonosos foram interpretados como material sedimentado nas baías interdistributárias. As AF-III e IV são correlacionadas ao Membro Triunfo (porção basal da Formação Rio Bonito).

ASSOCIAÇÃO FACIOLÓGICA $V$ É caracterizada por arenitos finos com estratificação cruzada de baixo ângulo ("swash") na porção basal, passando para laminação do tipo hummocky/swaley em direção ao topo. Sua espessura atinge cerca de $30 \mathrm{~m}$. Foi interpretado que esta $\mathrm{AF}$ representa o início da transgressão marinha que recobre os arenitos flúvio-deltáicos da AF-IV, culminando com o afogamento do sistema implantado anteriormente. Litoestratigraficamente corresponde ao Membro Paraguaçu (porção intermediária da Formação Rio Bonito).

ASSOCIAÇÃO FACIOLÓGICA VI É formada por espesso pacote de arenitos com intercalações de siltitos, folhelhos carbonosos e diversas camadas de carvão. Apresenta comumente laminação plano-paralela, truncada por onda, cruzada cavalgante (climbing), acamadamento "flaser" e "drapes" de argilas, bioturbação e fluidização, "wavy", "linsen" e "hum- 
mocky". Sua espessura atinge cerca de $30 \mathrm{~m}$. Esta AF foi considerada representar depósitos de sistema barreira-laguna, com interdigitações de sedimentos flúvio-deltaicos, tendo os sedimentos carbonosos sido originados em lagunas. É correlacionada ao Membro Siderópolis que constitui o terço superior da Formação Rio Bonito.

ASSOCIAÇÃO FACIOLÓGICA VII Esta AF ocorre somente na porção sul da área de estudo, atingindo cerca de $50 \mathrm{~m}$ de espessura. É formada por um conjunto de camadas com estrutura do tipo hummocky, interpretados como fácies de shoreface inferior, formados durante eventos de tempestades e preservados abaixo do nível de base de ação das ondas diárias (Walker \& Plint 1992), não deixando dúvidas que se originaram em um sistema deposicional marinho raso, correspondendo à Formação Palermo.

Superfícies cronoestratigráficas As superfícies cronoestratigráficas significativas identificadas são de três tipos: datum, limite de seqüência e superfície transgressiva (Fig. 6). O datum estabelecido é identificado pelo aumento do nível relativo do mar, diagnosticado pela ocorrência de bioturbações no topo da AF-II.

A superfície limite da seqüência 1 (LS1) marca o contato das rochas do embasamento cristalino com as rochas eo-permianas da Bacia do Paraná e representa um hiato de aproximadamente 300 milhões de anos.

A superfície transgressiva 1 (ST1) marca o início da transgressão glacio-marinha da AF-II sobre os sedimentos glacio-lacustres da AF-I, marcando a separação entre o trato de sistemas de mar baixo (TSMB1) e o trato de sistemas transgressivo (TST1); o trato de sistemas de mar alto não foi reconhecido.

A superfície (LS2) representa um período de rebaixamento no nível de base na bacia. Ela separa os sedimentos glacio-marinhos da AF-II dos sedimentos deltáicos da AF-III. Marca, portanto o limite da primeira seqüência deposicional, separando duas unidades litoestratigráficas, o Grupo Itararé e a Formação Rio Bonito.

Os sedimentos flúvio-deltáicos que iniciam a sedimentação na nova seqüência deposicional são recobertos por arenitos finos de shoreface superior e inferior, registrando uma nova transgressão marinha. A superfície que delimita estes diferentes pacotes de rochas e marca a zona de contato entre as associações de fácies III e IV dos sedimentos marinhos da AF-V é, portanto, denominada superfície transgressiva 2 (ST2).

A ocorrência das AF-VI e VII restrita ao furo de sondagem PB - 05 não permitiu identificar nenhuma outra superfície estratigráfica importante correlacionável nos demais furos.

\section{DISCUSSÃO DOS RESULTADOS}

Evolução estratigráfica $\mathrm{O}$ reconhecimento de estruturas na Bacia do Paraná tem sido alvo de investigações desde os anos 60/70, principalmente através de trabalhos de campo (Andrade \& Soares 1971; Soares 1974) e da análise morfoestrutural com base em fo- tos aéreas e em imagens orbitais e de radar (Soares et al. 1982). Desde então, conforme ressalta Rostirolla et al. (2000), a importância da herança tectônica na evolução da Bacia do Paraná foi destacada por diversos autores, com diferentes interpretações quanto à gênese das reativações, tais como movimentos verticais de blocos e associação com flexão da placa ou rifteamento durante a fase inicial de subsidência (e.g. Ramos 1970, Soares op. cit., Almeida 1980, Fúlfaro et al. 1982, Cordani et al. 1984, Brito Neves et al. 1984) ou, ainda, movimentos horizontais como reflexo de tensões induzidas pelas deformações nas bordas das placas (Zalán et al. 1987 e 1990). Milani (1997) fez referência a movimentos verticais, com a origem da bacia tendo sido influenciada por riftes na fase inicial, porém com deformações relacionadas a movimentos horizontais recorrentes nas fases posteriores. Porém, numa escala de evolução da Bacia do Paraná, há fatores geológicos complicadores, tais como a espessura da cobertura basáltica, as estruturas geradas por diques, sills e a tectônica pós-basalto, de modo que, apesar do conhecimento adquirido até o momento, muitas dúvidas ainda permanecem quanto à origem das estruturas, sua geometria original, distribuição e organização espacial, o tempo em que estiveram ativas e o papel que desempenharam ao longo da evolução da bacia (Artur \& Soares 2002).

No presente caso, o estudo de um intervalo estratigráfico menor e numa área com condições excepcionalmente favoráveis, onde a estrutura controladora e o pacote sedimentar são observados diretamente, permitiu caracterizar precisamente uma evolução estratigráfica fortemente controlada pela reativação do lineamento de Urussanga e reconstituir, com base na estratigrafia de seqüências, a evolução paleofisiográfica proposta a seguir.

Os diamictitos e ritmitos da AF-I representam o primeiro registro sedimentar da Bacia do Paraná na área de estudo. Neste estágio, zonas elevadas topograficamente eram expostas ao intemperismo, gerando sedimentos transportados para porções mais baixas. Assim, o lineamento de Urussanga controlava a existência de uma região mais baixa, provavelmente um vale glacial esculpido seguindo estruturas do embasamento que, nesta época, entretanto, não necessariamente teriam sido reativadas.

Com o término do período glacial, toda a área que antes se encontrava recoberta por gelo foi inundada. A partir de então, a variação positiva do nível de base e a tectônica tiveram grande importância na evolução do paleo-ambiente. A AF-II, que representa este período, é o registro da primeira transgressão marinha na região. A espessura de sedimentos desta associação na estrutura estudada foi muito grande, o que se deve, em parte, à área ainda constituir um paleo-vale. Por outro lado, também internamente à estrutura, esta associação apresenta variações de espessura da ordem de centenas de metros entre pontos distando menos de $2 \mathrm{~km}$ uns dos outros. Além disto, as investigações geofísicas efetuadas pelos mineradores demonstram 


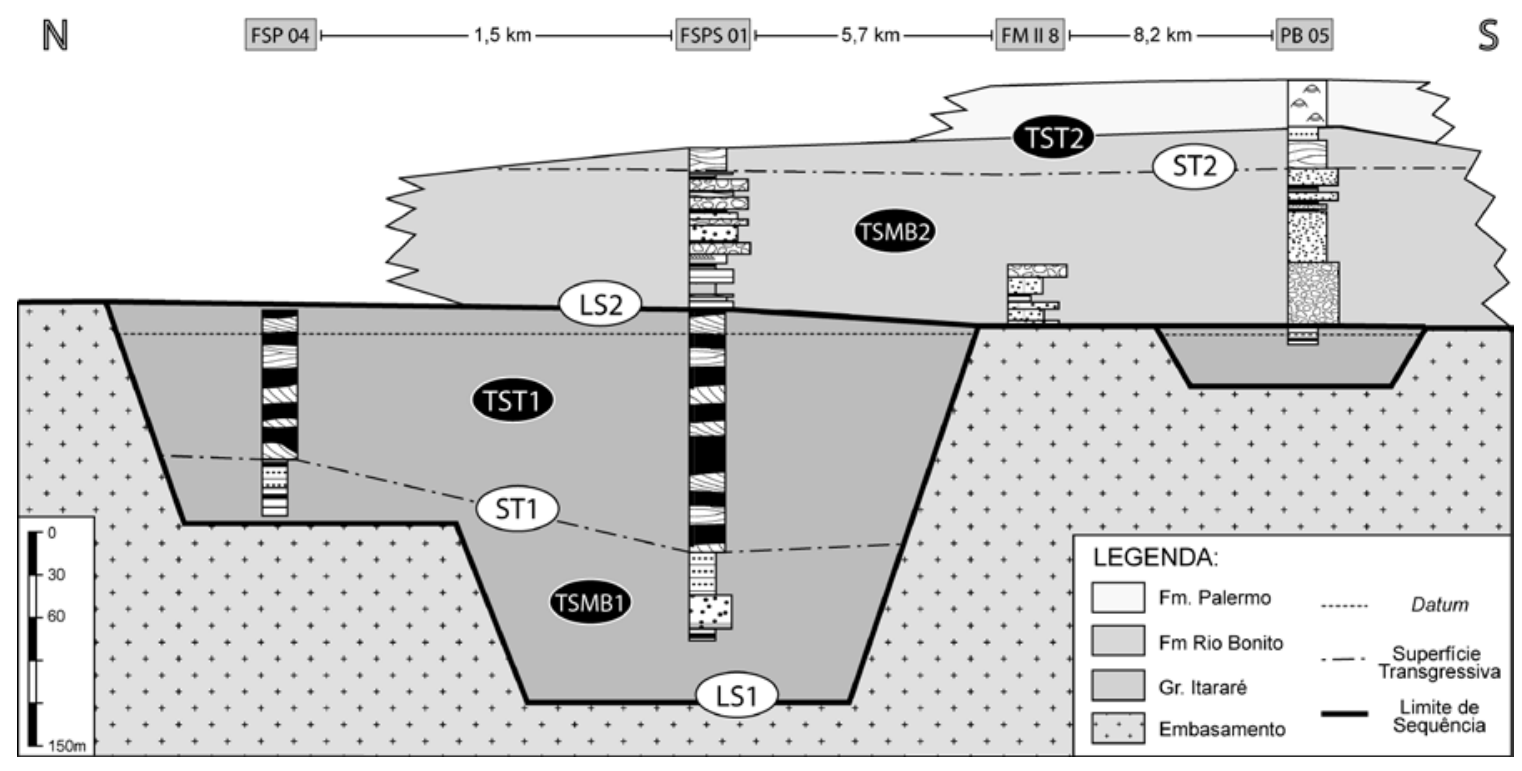

Figura 6 - Arcabouço cronoestratigráfico da área de estudo.

que a profundidade do embasamento varia também na ordem de uma centena de metros, tanto em perfis longitudinais como em perfis perpendiculares ao lineamento de Urussanga. Esta configuração é muito contrastante com aquela esperada para o fundo de um vale glacial. Semelhante mosaico de blocos seguramente não existe na cobertura nas adjacências do vale do Urussanga. Portanto, acredita-se que, ao mesmo tempo em que o nível relativo do mar subia, houve uma reativação na estrutura, gerando o denominado graben de Urussanga. Em síntese, o vale formado por uma erosão glacial que apenas seguia a orientação das estruturas (no tempo da AF-I), com a reativação destas, evoluiu para um graben (no tempo da AF-II).

O segundo estágio evolutivo é marcado inicialmente pelo recuo da linha de costa, devido à queda do nível relativo do mar, com conseqüente exposição e erosão de áreas outrora inundadas. Neste momento, a área do graben, por ser constituída por sedimentos, foi, provavelmente, mais afetada pela erosão do que as suas bordas constituídas por granitos. A superfície erosiva assim criada, a LS2, pode ocorrer, juntamente com a LS1, sobre o embasamento cristalino ou, individualmente, sobre os sedimentos marinhos da AF-II. Sobrepondo-se à LS2, encontram-se sedimentos (AFIII) depositados em ambiente tipicamente deltáico (pró-delta e frente deltáica). Este sistema progradou, conforme registram os arenitos finos a muito finos com estruturas características de pró-delta. Sobre estes, foram depositados sedimentos flúvio-deltáicos (AF-IV), num estágio em que o aporte sedimentar ainda era mais alto do que a subida do nível relativo do mar. A superfície ST2 marca uma nova mudança na paleofisiografia que passa para ambiente costeiro/estuarino representado fisicamente pelos arenitos (AFV) formados em zonas de shoreface inferior. Devido à fase erosiva (LS2), a área do graben ainda poderia ser uma área mais baixa exercendo, assim, um controle para a formação do estuário. A ausência da AF-V na borda sul do graben pode ser devida a não deposição ou a erosão posterior. $\mathrm{O}$ final do segundo estágio parece ter sido marcado por uma tendência de soerguimento regional mais acentuado na direção norte. Neste sentido, observa-se que a AFVI e a AFVII (Membro Siderópolis e Formação Palermo, respectivamente), que ocorrem no furo de sondagem PB-05, são ausentes na área mapeada. As isópacas das Formações Rio Bonito e Palermo (Zalán et al. 1986) indicam que suas espessuras na área seriam de apenas algumas dezenas de metros, de modo que elas poderiam ter sido facilmente erodidas. Durante o segundo estágio, não há evidências de que as estruturas que controlam o graben tenham sido reativadas.

Estudos em outras áreas da borda da Bacia do Paraná mostram que as ocorrências de sedimentos correlacionáveis à AF-I e à AF-II são restritas a baixos topográficos que podem representar paleofiordes no Rio Grande do Sul (Holz \& Carlucci 2000) e no norte de Santa Catarina (Canuto et al. 2001). Nestes estudos, não foi caracterizado que os paleovales tenham sido associados a grabens ou que tenham evoluído para estruturas deste tipo, mas esta hipótese não pode ser descartada, pois, pelo menos no primeiro caso, a coincidência entre a posição e orientação dos vales com os lineamentos do embasamento é muito destacada. Passando para uma escala de bacia, sabe-se que ocorreu uma nítida aceleração na subsidência tectônica e total na Bacia do Paraná coincidindo com o início da deposição do Grupo Itararé (Canuto et al. op. cit.). Além disso, as isópacas (Zalán et al. 1987) do Grupo Itararé mostram uma orientação muito acentuada na direção NW-SE, que não persistiu no tempo da deposição da Formação Rio Bonito cujas isópacas têm direção N-S a NE-SW. Nesta época, a borda leste da Bacia do Paraná 
foi afetada por um soerguimento, ligado por Zalán et al. (1987) à orogenia Tardi-herciniana, cujo limite sul provavelmente se encontra na área do presente estudo. Os dados locais corroboram, portanto, os modelos em escala regional da sedimentação na Bacia do Paraná.

\section{Implicações na gênese e prospecção de filões de} fluorita A localização dos filões nas proximidades de lineamentos NW-SE, constatada por diversos autores (e.g. Horbach \& Marimon 1980), foi adotada como critério prospectivo sem que se procurasse compreender qual a ligação existente entre os filões e estas estruturas. $\mathrm{O}$ mesmo ocorreu com a presença de cobertura sedimentar na adjacência dos filões, pois o hiato de 200Ma existente entre as rochas sedimentares e os filões não estimulou a investigação de suas relações. Somam-se, ainda, dois aspectos. O primeiro é a presença de relictos de cobertura sedimentar na parte leste do distrito ser entendida como uma evidência de que a Bacia do Paraná já ocupou toda a área. Assim, o papel da cobertura no aprisionamento dos fluidos mineralizantes também teria corrido em todo o distrito. Ou seja, a presença de cobertura num local não o definiria como mais propício para a formação de um filão; ela o definiria como mais propício para a preservação de filões à erosão. Bastaria apenas, portanto, localizar áreas com cobertura próxima, não havendo motivos para investigar a razão de sua preservação. O segundo refere-se à ausência de cobertura num dado local ter sido atribuída apenas à erosão (nunca se pensou em não deposição). E a erosão, por sua vez, ter sido atribuída a soerguimentos mais recentes e de escala regional (Horbach \& Marimon, op. cit., Bastos Neto 1990), fazendo com que as tentativas de delimitar áreas menos afetadas por erosão (Flores et al. 1993, Jelinek 2002) fossem efetuadas apenas na escala regional.

Contrariamente ao anteriormente suposto, a presença de cobertura sedimentar no distrito pode não ter sido generalizada. Mais especialmente nas partes leste e norte do distrito, a sedimentação pode ter sido restrita a paleovales, que podem ter sido associados a abatimentos tectônicos e/ou a erosão glacial fortemente controlada por estruturas. Os afloramentos do Grupo Itararé situados ao norte da lagoa de Imaruí (Fig. 2), a mais de $30 \mathrm{~km}$ da atual borda da Bacia do Paraná, devem estar ligados a um paleovale - possivelmente um dos mais extensos e mais profundamente esculpidos no embasamento do distrito e onde a espessura de sedimentos pode ter sido muito maior do que os $250 \mathrm{~m}$ da AFII no graben de Urussanga, permitindo, portanto, sua preservação. Há cerca de $130 \mathrm{Ma}$, quando se iniciava a formação dos filões de fluorita, a presença de cobertura sedimentar foi determinante no aprisionamento de fluidos e, conseqüentemente, na gênese e distribuição dos filões que, conforme indicam os estudos de inclusões fluidas da fluorita (Dardenne \& Savi 1984, Bastos Neto 1990), formaram-se a profundidades de, pelo menos, $500 \mathrm{~m}$. Nas partes oeste e sul do distrito, a cobertura sedimentar, somada aos derrames basálticos, atingiu espessuras desta ordem, conforme mostram as isópacas das formações da Bacia do Paraná (Zalán et al. 1986). Nas partes norte e leste, entretanto, as espessuras foram muito menores, de modo que as condições de cobertura necessárias à formação dos filões foram restritas aos lineamentos NW-SE. Posteriormente, a erosão gerou a configuração atual do distrito e mascarou as relações entre lineamentos NW-SE, cobertura e filões que só puderam ser reconstituídas graças ao estudo do quase oculto graben de Urussanga.

$\mathrm{O}$ controle dos lineamentos NW-SE na distribuição espacial dos filões foi exercido também em escala local, haja vista a localização dos maiores filões (Segunda Linha Torrens Principal e São Pedro) ainda no domínio do graben. Esta distribuição sugere que a migração dos fluidos mineralizantes em profundidades maiores (lixiviando o F dos granitos) foi fortemente controlada pelas estruturas do lineamento NW-SE. Ao encontrarem as estruturas NNE-SSW, então reativadas e abertas, os fluidos ascenderam até o nível da base da cobertura sedimentar, iniciando a deposição da fluorita. Por estas mesmas estruturas, os fluidos migraram longitudinalmente e estabeleceram-se gradientes geoquímicos, com a formação dos principais filões nas proximidades do ponto de intersecção e de filões sucessivamente menores e com menores teores de $\mathrm{CaF}_{2}$, conforme aumenta a distância da intersecção. Esta configuração é observada no lineamento Canela Grande tanto ao norte como ao sul do graben Urussanga.

\section{CONCLUSÕES E CONSIDERAÇÕES FINAIS A} origem das estruturas de direção NW-SE, como o lineamento de Urussanga, é relacionada à evolução do embasamento. Este lineamento guiou a formação de um vale glacial onde foram depositados os primeiros sedimentos da Bacia do Paraná no DFSC, os diamictitos e ritmitos glacio-lacustres da AF-I. Subseqüentemente, o lineamento foi reativado originando um graben onde foram depositados $250 \mathrm{~m}$ de arenitos e pelitos de ambiente marinho raso (AF-II). Sobre a superfície LS2, depositaram-se arenitos de frente deltáica (AF-III), marcando o início da progradação do sistema fluvio-deltáico que se instalou na região (sedimentação não restrita ao graben), e arenitos finos a grossos/conglomeráticos (AF-IV), representando a progradação da porção mais continental de um sistema flúvio-deltáico. Não há evidências de que as estruturas NW-SE tenham sido então reativadas. Uma superfície ST2 marca nova mudança paleofisiográfica, com a passagem para ambiente costeiro/estuarino (arenitos de shoreface inferior da $\mathrm{AF}-\mathrm{V}$ ); a área do graben exerceu controle sobre a formação do estuário. $\mathrm{O}$ final deste estágio foi marcado por uma tendência de soerguimento regional mais acentuado na direção norte, onde a AFVI (depósitos de sistema barreira-laguna, com interdigitações de sedimentos flúvio-deltaicos) e a AFVII (depósito marinho raso) depositaram-se com espessuras reduzidas e foram erodidas. Formações mais jovens da Bacia do Paraná podem ter sido depositadas no DFSC com espessuras totais de até $400 \mathrm{~m}$ na 
parte oeste e com espessuras muito menores (ou não foram depositadas) nas partes norte e leste. Estas foram afetadas por forte soerguimento e nelas ocorrem relictos da Formação Rio do Sul associados a lineamentos NW-SE que devem representar paleovales ou grabens como o de Urussanga.

Apesar da área deste estudo ser a mais estudada de todo o distrito, a ótica diferente aqui adotada (a das estruturas NW-SE) gerou observações e conclusões originais sobre os depósitos, mesmo sem estes terem sido objetos de estudos específicos: a distribuição dos filões em relação ao lineamento NW-SE é eminentemente zonada, as dimensões e, principalmente, os teores dos filões diminuem à medida que eles estão mais distantes das estruturas NW-SE. Este fato evidencia que a migração dos fluidos mineralizantes em profundidades maiores foi fortemente controlada pelas estruturas do lineamento NW-SE, que elas ascenderam até o nível da base da cobertura sedimentar pelas estruturas NNE-SSW, então reativadas e abertas, e por elas migraram longitudinalmente, depositando fluorita e estabelecendo gradientes geoquímicos.

Conforme indicam os estudos geoquímicos efetuados por diversos autores, a presença de cobertura sedimentar relativamente espessa foi fundamental à gênese da mineralização. Julgava-se, entretanto, que uma cobertura assim existiu por toda a área do distrito, de modo que a presença de rochas sedimentares num dado local significaria apenas uma evidência de que filões poderiam ter sido preservados à erosão. Os resultados do presente trabalho mostram que, apesar do hiato de cerca de 200Ma existente entre as rochas da Bacia do Paraná na área do DFSC e os filões de fluorita, as relações entre os sedimentitos e estes depósitos são, na verdade, muito mais estreitas. Elas remontam à época da sedimentação na Bacia do Paraná, pois uma cobertura idealmente espessa certamente nunca existiu uniformemente distribuída por todo o distrito, de modo que o entendimento dos controles sobre a sedimentação ocorrida muito antes da gênese dos filões, este sim, é que permite estabelecer onde existiram locais com as condições de cobertura mínima necessária para formação dos depósitos. Neste sentido, o presente trabalho revelou o papel exercido pelos lineamentos de direção NW-SE como o elemento de ligação que une a história de parte da sedimentação bacia à gênese das mineralizações de fluorita, o que, por sua vez, explica o porquê de filões associados a lineamentos NNE-SSW se localizarem preferencialmente nas proximidades das intersecções com os lineamentos NWSW, uma relação empiricamente estabelecida, válida, mas nunca antes explicada.

Agradecimentos À CAPES pela concessão de bolsa de mestrado a Mateus Marcili; à Companhia NitroQuímica pela permissão de consulta a relatórios internos e acesso às litotecas; à CPRM (Superintendência Regional de Porto Alegre). Ao Geólogo Clóvis Savi pela colaboração nos trabalhos de campo. Aos revisores pelas críticas e sugestões que contribuíram para a melhoria do trabalho.

\section{Referências}

Almeida F.F.M. 1980. Tectônica da Bacia do Paraná no Brasil. São Paulo, Relatório Paulipetro, 187p.

Amaral G., Bushee J., Cordani U.G., Kawashita K., Reynolds J.H. 1967. Potassium-argon ages of alkaline rocks from southern Brazil. Geochimica et Cosmochimica Acta, 31:117-142.

Andrade S.M. \& Soares P.C. 1971. Geologia do Centro-Leste do Estado de São Paulo. Relatório Petrobrás-Desul Rel. 407 (Disponivel CPRM Rio de Janeiro).

Angeiras A.G. \& Teixeira C.A.S. 1965. Nota sobre a gênese da fluorita de Morro da Fumaça. Ver. Eng. Min. Met. Rio de Janeiro, 42(250):185-189.

Artur P.C. \& Soares P.C. 2002. Paleoestruturas e petróleo na Bacia do Paraná, Brasil. Revista Brasileira de Geociências, 32(4):433-448

Asmus H.E. 1984. Geologia da Margem Continental Brasileira. In: Schobbenhaus C., Campos D.A., Derze G.R., Asmus H.E. (eds.) Geologia do Brasil. Brasília, DNPM, p. 443-472.

Bastos Neto A.C. 1986. Relatório da pesquisa na área da Mina I. DNPM (9.935/67). Rel. Ined. (Disponível na biblioteca do Departamento Nacional da Produção Mineral, Florianópolis).

Bastos Neto A.C. 1990. Le district à fluorine de Santa Catarina: minéralisations et altérations hydrothermales dans leur cadre géodynamique. Tese de doutoramento, Université d'Orleans, $420 \mathrm{p}$.

Bastos Neto A.C., Touray J.C., Charvet J., Dardenne M. 1992. Controle tectonique des minéralisations à fluorine de Santa Catarina, Brésil: filons en décrochement et en extension. Chron. Rech. Min., 507:43-52.

Bastos Neto A.C., Touray J.C., Dardenne M. 1996. Géochimie isotopique $(\mathrm{dD})$ appliquée à l'étude des inclusions fluides de la fluorine du district de Santa Catarina (Brésil): une discussion sur l'origine des solutions minéralisées. An. Acad. bras. Ci., 68(2):213-221.

Bhattachrya J.P. \& Walker R.G. 1992. Deltas. In: Walker R.G. \& James N.P. (eds.) Facies Models - response to sea level change. Geological Association of Canada. p. 157-177.

Brito Neves B.B., Fuck R.A., Cordani U.G., Thomaz Filho A. 1984. Influence of basement structures on the evolution of the major sedimentary basins of Brazil: a case of tectonic heritage. Journal of Geodynamics, 1:495-510.

Canuto J.R., Santos P.R., Rocha A.C. 2001. Estratigrafia de seqüências do Subgrupo Itararé (Neopaleozóico) no leste da Bacia do Paraná, nas regiões sul do Paraná e norte de Santa Catarina, Brasil. Rev. Bras. Geoc., 31:107-116

Cordani U.G., Neves B.B.B., Fuck R.A., Porto R., Thomaz Filho A., Cunha F.M.B. 1984. Estudo preliminar de 
integração do Pré-cambriano com os eventos tectônicos das bacias sedimentares brasileiras. Rio de Janeiro: PETROBRAS, Série Ciência-Técnica-Petróleo, n.15, $70 \mathrm{p}$.

Dardenne M.A. \& Savi C.N. 1984. Geologia e geoquímica dos filões de fluorita Segunda Linha Torrens e Cocal (SC). Rev. Bras. Geociências, 14(2):120-127.

Dardenne M.A., Ronchi L.H., Bastos Neto A.C., Touray J.C. 1997. Geologia da fluorita. In: Schobbenhaus S., Queiroz E.T., Coelho C.E.S. (eds.) Principais depósitos minerais do Brasil. DNPM/CPRM, Volume IV-b, p. 479-508.

Dias M.E.R. 1993. Associações microflorísticas dos paleovales do Grupo Itararé no Rio Grande do Sul, Permiano da Bacia do Paraná, Brasil. Porto Alegre, Pesquisas, 20(2):132-140.

Ferreira A.C. \& Almeida T.I. 1989. Tectônica transcorrente e imagens TM-LANDSAT aplicadas à prospecção de fluorita e barita em Santa Catarina. Rev. Bras. de Geociências, 19(2):207-223.

Flores J.A.A., Lisboa N.A., Baptista P.R.D. 1993. Caracterização morfotectônica e morfoestrutural do Sudeste de Santa Catarina. Geociências, 12(1):61-70.

Fragoso César A.R. 1980. O Cráton Rio de La Plata e o Cinturão Dom Feliciano no Escudo Uruguaio-Sul_rioGrandense. In: SBG, Congr. Bras. Geol., 31, Camboriú, Anais, 5:2879-2892.

Fúlvaro V.J., Saad A.R., Santos M.V., Vianna R.B. 1982. Compartimentação e evolução tectônica da Bacia do Paraná. Revista Brasileira de Geociências, 12(4):590610.

Hackspacher P.C. \& Flores J.A.A. 1987. Contribuição sobre o controle estrutural das jazidas de fluorita na estrutura de Canela Grande, sudeste de Santa Catarina. In: Simpósio Sul-Brasileiro de Geologia, 3, Curitiba, Atas, 543-550.

Hoff R. 2002. Integração de dados geológicos, de sensoriamento remoto, espectrorradiométricos $e$ geofísicos aplicada à prospecção de depósitos filoneanos de fluorita hidrotermal no Sudeste de Santa Catarina. Tese de Doutoramento, Instituto de Geociências, Universidade Federal do Rio Grande do Sul, 167 p.

Hoff R., Bastos Neto A.C., Rolim S.B.A. 2002. Contribuição do estudo aeromagnetométrico e de Imagens Orbitais (TM-LANDSAT 5) ao conhecimento do arcabouço geológico do Distrito Fluorítico de Santa Catarina (Brasil) e suas implicações para a prospecção de fluorita. Porto Alegre. Pesquisas em Geociências, 29(2):37-52.

Holz M. \& Carlucci R. 2000. Litoestratigrafia, Estratigrafia de Seqüências e Evolução Paleofisiográfica da zona de borda da Bacia do Paraná no Rio Grande do Sul durante o Eo-Permiano. In: Holz M. \& De Ros L.F. (eds.) Geologia do Rio Grande do Sul, CIGO/UFRGS, p. 303322.

Horbach R. \& Marimon R.G. 1980. Esboço da evolução tectônica e seu significado na gênese dos depósitos de fluorita no sudeste catarinense. In: Congresso Brasileiro de Geologia, 31, Camboriú, Anais, 3:1540-1551.

Jelinek A.R.J. 1997. Análise por traços de fissão em apatitas (AFTA) da encaixante dos depósitos de fluorita filoneana do Sudeste Catarinense: uma evolução hidrotermal polifásica. Dissertação de Mestrado, Instituto de
Geociências, Universidade Federal do Rio Grande do Sul, $200 \mathrm{p}$.

Jelinek A.R.J. 2002 Evolução geológica do Distrito Fluorítico de Santa Catarina: estudo integrado de mineralogia, geoquímica e termotectônica por traços de fissão em apatita. Tese de Doutoramento, Instituto de Geociências, Universidade Federal do Rio Grande do Sul, 2v, 204 p.

Krebs A.S.J., Menezes F.N.R., Rodrigues T.L.N. 1984. Carvão e relação com sistemas deposicionais na região de Taió, Santa Catarina. In: Congresso Brasileiro de Geologia, 33, Rio de Janeiro, Anais, p. 1204-22.

Martins Filho P.J., Ronchi L.H., Bastos Neto A.C., Althoff F.C. 2003. Contribuição do estudo da rais do filão Cocal (inclusões fluídas e ETR) ao modelamento dos depósitos minerais de fluorita do sudeste catarinense. In. Ronchi L.H. \& Althoff F.J. (org.) Caracterização e modelamento de depósitos minerais. São Leopoldo, Editora Unisinos, p. 243-266.

Miall A.D. 1992. Alluvial deposits. In: Walker R.G. \& James N.P. (eds.) Fácies Models - response to sea level change. Geological Association of Canadá, p.119-142.

Milani E.J. 1997. Evolução tectôno-estratigráfica da Bacia do Paraná e seu relacionamento com a geodinâmica fanerozóica do Gondwana Sul-ocidental. Tese de Doutoramento, Instituto de Geociências, Universidade Federal do Rio Grande do Sul, 2v, 255 p.

Morgental A. 1984. Caracterização dos depósitos de fluorita. Projeto fluorita no sudeste de Santa Catarina. Relatório Preliminar, Etapa 2. Porto Alegre, CPRM, 130p.

Morgental A. 1985. Prospecção hidrogeoquímica para fluorita no sudeste catarinense. In: SBG, Simp. Sul Bras. Geol., 2, Florianópolis, Atas, p. 234-247.

Morgental A. \& Kirchner C.A. 1983. Síntese do mapa previsional do Distrito Fluorítico de Santa Catarina. In: SBG, Simp. Bras. de Geol., 1, Porto Alegre, Atas, p. 294306

Putzer H.F. 1953. Distrofismo germanótipo e sua relação com o vulcanismo basáltico na parte meridional de Santa Catarina. Bol. Soc. Geol., 2(1):37-74.

Ramos A.N. 1970. Aspectos paleo-estruturais da Bacia do Paraná e sua influência na sedimentação. Boletim Técnico da Petrobrás, 13(3/4):85-93.

Rocha F.F.N. 1997. Geologia e geoquímica dos filões de fluorita da parte norte do Distrito Fluoritico de Santa Catarina. Dissertação de Mestrado, Instituto de Geociências, Universidade Federal do Rio Grande do Sul, 188 p.

Rostirolla S.P., Assine M.L., Fernandes, L.A., Artur P.C. 2000. Reativação de paleolineamentos durante a evolução da Bacia do Paraná - O exemplo do alto estrutural de Quatiguá. Revista Brasileira de Geociências, 30(4):639648.

Sallet R.G. 1988. Étude pétrologique et métallogénique d'un secteur du district à fluorine de Santa Catarina, Brésil. Les granitoïdes précambriens monzonitiques source probable de la fluorine filonienne post-jurassique. Tese de doutoramento, Université de Paris, 233 p.

Sallet R.G., Moritz R., Fontignie D. 1996. 87Sr/86Sr systematics at the post-jurassic Santa Catarina Fluorite District, Brazil. Genetic model and age implications. In: 
SBG, Congr. Bras. Geol., 39, Salvador, Anais, 7:328331.

Savi C.N. 1980. Gênese e controle das mineralizações de fluorita da região de Criciúma (SC). Dissertação de Mestrado, Instituto de Geociências, Universidade de Brasília, 112p.

Savi C.N. \& Dardenne M.A. 1980. Zonação, paragênese e controles da mineralização de fluorita do filão Segunda Linha Torrens, Município de Morro da Fumaça, SC. In: SBG, Cong. Bras. Geol, 31, Camboriú, Anais, 3:17431757.

Scheibe L.F. 1986. Geologia e petrologia do distrito alcalino de Lages, SC. Tese de Doutoramento em Geociências, Universidade de São Paulo, 224 p.

Schneider R.L., Mühlmann H., Tommasi E., Medeiros R.A., Daemon R.F., Nogueira A.A. 1974. Revisão estratigráfica da Bacia do Paraná. SBG, Congresso Brasileiro de Geologia, 32, Salvador - BA, Anais, 4:1378-89.

Silva M.A.S. 2000. Criciúma, Folha SH.22-X-B. Estado de Santa Catarina. Programa levantamentos geológicos básicos do Brasil. Brasília, CPRM, escala 1:250000.

Soares P.C. 1974. Elementos estruturais da parte nordeste da Bacia do Paraná: Classificação e Gênese. In: SBG, Cong. Brás. de Geol., 28, Porto Alegre, Anais, 1:107-121.

Soares P.C., Barcelos P.E., Csordas S.M. 1982. Análise, interpretação e integração de lineamentos a partir de imagens (Radar-Landsat) e suas relações com a tectônica da Bacia do Paraná. São Paulo: Relatório RT342/82, Paulipetro. Consórcio CESP/IPT.

Tassinari C.G. \& Flores J.A. 1992. Aplicação dos isótopos de Sr e Nd na mineralização de fluorita do poço 5, Segunda Linha Torrens, sudeste de Santa Catarina. In: SBG,
Cong. Bras. Geol., 37, São Paulo, Anais, 1:259-260.

Teixeira C.A.S. 1969a. Relatório de datações geocronológicas do projeto básico da região leste e do projeto específico da fluorita. Porto Alegre, DNPM, 39p.

Walker R.G. 1992. Fácies, fácies models and modern estratigraphy concepts. In: Walker R.G. \& James N.P. (eds.) Facies models - response to sea level change. Geological Association of Canada, p. 1-14.

Walker R.G \& Plint A.G. 1992. Wave and storm dominated shallow marine system. In: Walker R.G. \& James N.P. (eds.) Facies models - response to sea level change. Geological Association of Canada, p. 219-238.

Zalán P.V., Wolff S., Astolfi M.A.M., Vieira L.S., Conceição J.C.J. Appi V.T., Neto E.V.S., Cerqueira J.R., Merques A. 1990. The Paraná Basin, Brazil. In: Leighton M.W., Kolata D.R., Oltz D.F., Eidel J.J. (eds.) Interior cratonic Basins. Tulsa: American Association of Petroleum Geologists Memoir 51, p. 681-708.

Zalán P.V., Wolff S., Astolfi M.A.M., Vieira L.S., Conceição J.C.J., Appi V.T., Neto E.V.S., Cerqueira J.R., Marques A. 1990. The Paraná Basin, Brazil. Tulsa: AAPG Memoir, 51:681-708.

Zalán P.V., Wolff S., Conceição J.C.J., Astolfi M.A.M., Vieira L.S., Appi V.T., Zannoto O.A. 1987. Tectônica e sedimentação da Bacia do Paraná. In: Simp. Bras. de Geol., 3, Curitiba, 1:441-473.

Manuscrito ID 10541

Submetido em 13 de fevereiro de 2008 Aceito em 10 de dezembro de 2009 